\title{
Inovação social no contexto da agricultura urbana em Florianópolis: o caso do Centro de Estudos e Promoção da Agricultura de Grupo
}

Pesquisas internacionais revelam que alguns centros urbanos elaboraram estudos para projetar políticas regulatórias relacionadas à agricultura urbana, adotando legislação favorável e reconhecendo a importância da agricultura urbana. Este estudo analisou a inovação social no contexto da agricultura urbana em Florianópolis, utilizando o Centro de Estudos e Promoção da Agricultura de Grupo - Cepagro como objeto de estudo. O Cepagro, a partir de suas redes formadas por diferentes atores, tem colocado o tema da agricultura urbana em debate e contribuído para que importantes dispositivos legais promovam inovação social no território, articulando discussões e desenvolvido ações em torno do tema da agricultura urbana e segurança alimentar. Resultados do estudo qualitativo revelaram que a atuação do Cepagro constituiu importantes inovações sociais no território, articulando agricultura urbana, segurança alimentar e desenvolvimento comunitário, além de colaborar com a elaboração e implementação de políticas públicas para o setor e estar nos espaços de representação dos conselhos de políticas públicas da cidade.

Palavras-chave: Inovação social; Desenvolvimento territorial sustentável; Agricultura urbana; Segurança alimentar.

\section{Social innovation in the context of urban agriculture in Florianópolis: the case of the Center for Studies and Promotion of Group Agriculture}

\begin{abstract}
International surveys reveal that some urban centers have developed studies to design regulatory policies related to urban agriculture, adopting favorable legislation and recognizing the importance of urban agriculture. This study analyzed social innovation in the context of urban agriculture in Florianópolis, using the Centro de Estudos e Promoção da Agricultura de Grupo - Cepagro as the object of study. The Cepagro, based on its networks formed by different actors, has put the topic of urban agriculture on debate and contributed to important legal provisions promoting social innovation in the territory, articulating discussions and developing actions around the topic of urban agriculture and food security. Results of the qualitative study revealed that Cepagro's performance constituted important social innovations in the territory, articulating urban agriculture, food security and community development, in addition to collaborating with the elaboration and implementation of public policies for the sector and being in the spaces of representation of the councils of public policies of the city.
\end{abstract}

Keywords: Social innovation; Sustainable territorial development; Urban agriculture; Food security.

Topic: Planejamento, Gestão e Políticas Públicas Ambientais

Reviewed anonymously in the process of blind peer.
Received: 04/06/2021 Approved: 29/06/2021
Luciana Francisco de Abreu Ronconi

Universidade do Estado de Santa Catarina, Brasil

http://lattes.cnpq.br/6402637129940953

http://orcid.org/0000-0001-7916-7468

luciana.ronconi@udesc.br

Bernadete de Lourdes Bittencourt (iD

Instituto Politécnico de Bragança, Brasil

http://lattes.cnpq.br/3952786520378236

http://orcid.org/0000-0002-1620-314X

bernadete@ua.pt

Gabriel Bertimes Di Bernardi Lopes (10)

Universidade do Estado de Santa Catarina, Brasil

http://lattes.cnpq.br/7872432677803420

http://orcid.org/0000-0001-9195-5934

gabriel.lopes@udesc.br
Referencing this:

RONCONI, L. F. A.; BITTENCOURT, B. L.; LOPES, G. B. B.. Inovação social no contexto da agricultura urbana em Florianópolis: o caso do Centro de Estudos e Promoção da Agricultura de Grupo. Revista Ibero Americana de Ciências Ambientais, v.12, n.6, p.635-650, 2021. DOI: http://doi.org/10.6008/CBPC2179-6858.2021.006.0053 


\section{INTRODUÇÃO}

No Município de Florianópolis foi aprovada a Lei 9.355/2013, um dispositivo relacionado à segurança alimentar, que criou a Política Municipal de Segurança Alimentar e Nutricional Sustentável de Florianópolis. A política tem por objetivo, promover ações e políticas destinadas a assegurar o direito humano à alimentação adequada e o desenvolvimento integral da pessoa humana. É importante destacar que de acordo com o Art. 6 da referida lei, o Sistema Municipal de Segurança Alimentar e Nutricional Sustentável é formado pela Conferência Municipal de Segurança Alimentar e Nutricional Sustentável, pelo Conselho Municipal de Segurança Alimentar e Nutricional Sustentável de Florianópolis, pela Coordenadoria Municipal de Segurança Alimentar e Nutricional Sustentável, pela Câmara Intersetorial de Segurança Alimentar e Nutricional Sustentável, pelo Plano Municipal de Segurança Alimentar e Nutricional Sustentável e pelas instituições privadas, com ou sem fins lucrativos, ligadas à segurança alimentar sustentável.

Em julho 2016 foi criado, através do Decreto 16.408, o Grupo de Trabalho para a elaboração de estudo para criação do Programa Municipal de Agricultura Urbana. Se tem nesse momento, no âmbito municipal, a incorporação do tema da agricultura urbana nos debates sobre a segurança alimentar e na criação de dispositivos legais.

O Grupo de Trabalho (GT) teve como integrantes os representantes de associações, fundações, institutos, órgãos representativos de classe, demais entidades da sociedade civil, servidores de outras entidades públicas e especialistas nas áreas envolvidas na proposta. Ficou estabelecido no Art. 5, do referido Decreto, que o Programa deveria, dentro outros, contemplar

A agricultura urbana de base agroecológica, assim como contemplar objetivos de práticas agrícolas em meio urbano tais como: a melhoria das condições nutricionais e de saúde, de lazer, de saneamento, valorização da cultura, educação ambiental, desenvolvimento sustentável e melhoria urbanística da cidade.

Como resultado da articulação de diferentes atores no debate em torno da agricultura e contemplando o que ficou estabelecido durante o Grupo de Trabalho criou-se o Programa Municipal de Agricultura Urbana através do Decreto 17.688 de junho de 2017. Algumas das prioridades do programa são: possibilitar à população acesso a alimentos saudáveis e de baixo custo provenientes da agricultura urbana, incentivar o cultivo de hortas urbanas em espaços públicos, apoiar a comercialização de produtos orgânicos resultantes da Agricultura Urbana, desenvolver atividades pedagógicas com a população e por fim, desenvolver tecnologias sociais de base agroecológica de forma que a agricultura urbana seja promovida. Processos referentes a prática agroecológica como gestão de resíduos orgânicos através de compostagem e vermicompostagem, produção agroecológica de viveiros de mudas e sementes e aumento da biodiversidade são, ainda, contemplados pelo programa.

No Programa Municipal de Agricultura Urbana, vinculado à Superintendência de Pesca, Maricultura e Agricultura da Prefeitura de Florianópolis, o site da Prefeitura divulga a importância da consolidação das parcerias interinstitucionais com gestão compartilhada, que envolveu quinze órgãos da administração municipal. A intersetorialidade foi considerada uma importante estratégia para fortalecer a gestão pública e reuniu 'indivíduos e instituições, de forma democrática e participativa, em torno de objetivos comuns'. Em 
relação à agricultura urbana o Programa busca 'resgatar técnicas de cultivo históricas das comunidades tradicionais e de vanguarda, valorizando o conhecimento empírico associado ao conhecimento científico na busca de alimentos com alta qualidade nutricional e livres de agrotóxicos'.

Especialmente o Decreto 17.688/2017, que criou o Programa Municipal de Agricultura Urbana e deu as bases parta a formulação da Política Municipal de Agroecologia e Produção Orgânica de Florianópolis (PMAPO), foi um marco para a cidade no que se refere à implementação de uma política pública na área da agricultura urbana.

Esse programa traduziu as preocupações e demandas da sociedade e se voltaram para o desenvolvimento sustentável; tratou-se de um processo inovador no território do qual o Centro de Estudos e Promoção da Agricultura de Grupo - Cepagro teve um papel de grande articulador. Uma experiência que se destaca, principalmente no que se refere à criação de dispositivos legais e estruturas institucionais, tem sido desenvolvida pelo Centro de Estudos e Promoção da Agricultura de Grupo - Cepagro. Trata-se de uma organização da sociedade civil que historicamente tem articulado discussões e desenvolvido ações em torno do tema da segurança alimentar e agricultura urbana. A referida organização, por integrar diferentes arenas públicas e realizar interlocução com diferentes esferas dos governos e da sociedade civil, tem inovado em suas práticas não apenas por buscar soluções aos problemas do desenvolvimento sustentável, mas também por ter incidência política.

A partir da sua articulação em rede o Cepagro teve um papel fundamental para a aprovação do Decreto 17.688 de junho de 2017, que cria e institui o Programa Municipal de Agricultura Urbana na cidade de Florianópolis. Assim, a atuação do Cepagro se constitui em uma importante inovação social no território, pois além de articular a agricultura urbana com o desenvolvimento comunitário e com a segurança alimentar, objetiva ter incidência política, isto é, estar nos espaços de representação, como os conselhos de políticas públicas e propor políticas públicas no campo da agricultura urbana.

Já em 2018, com a criação da Lei Municipal 10.392 de junho de 2018 que dispõe sobre a Política Municipal de Agroecologia e Produção Orgânica de Florianópolis (PMAPO), ficou consolidada a preocupação do município com as questões da agroecologia e a agricultura urbana. A Política Municipal tem como objetivo geral

Integrar, articular e adequar políticas públicas, programas e ações indutoras da transição agroecológica e da produção orgânica e de base agroecológica, contribuindo para o desenvolvimento sustentável e a qualidade de vida da população, por meio do uso sustentável dos recursos ambientais e da oferta e do consumo de alimentos saudáveis, de origem animal e vegetal.

O objetivo deste trabalho foi analisar a inovação social no contexto da agricultura urbana na cidade de Florianópolis e de que maneira diferentes atores, a partir de suas redes, tem colocado o tema em debate e contribuído para que importantes dispositivos legais organizem e promovam essa inovação social no território, utilizando como objeto de estudo o caso do Centro de Estudos e Promoção da Agricultura de Grupo - Cepagro. 


\section{REVISAO TEÓRICA}

\section{A inovação social no contexto da agricultura urbana}

As inovações sociais traduzem as preocupações da sociedade e se voltam mais amplamente para o desenvolvimento socioeconômico. Com efeito, embora a inovação social possa surgir de iniciativas dos cidadãos o setor público pode fomentar e apoiar a inovação mediante a implementação de políticas públicas bem como ampliar o alcance de uma inovação replicando a sua implantação em todo o território. Através de políticas públicas, leis e reformas, os decisores políticos podem se constituir em promotores e propagadores de inovação social por meio legal, institucional, financeiro e material. Todavia, diferentes atores participam dos processos de elaboração das políticas públicas, a partir de seus conhecimentos, experiências e demandas, direcionadas a atender as situações problemáticas (MULGAN et al., 2007).

Decorrem da vontade coletiva para propulsar o desenvolvimento socioeconômico do território. Assim, a inovação social é percebida como processo, serviço, produto, motor de mudança no território, que resulta em novas práticas e formas de pensar, de resolver os problemas mais prementes do lugar e transformá-lo num ambiente inovador de desenvolvimento socioeconômico (FONTAN et al., 2004; HILLIER et al., 2004).

Geralmente ocorre em pequena escala ou num conjunto de microprojetos, algumas vezes isolados e frágeis. Esse aspecto pede a cooperação entre organizações e sociedade para suportar a inovação social em todo o seu processo. Dessa cooperação surge um sistema de inovação social territorial, que revela a dimensão social e política da inovação social na construção de novas práticas sociais (HILLIER et al., 2004; KLEIN et al., 2009).

Novas estratégias para o desenvolvimento de sistemas produtivos estão emergindo em nível territorial. De um ponto de vista histórico, elas constituem uma nova forma de organização do setor econômico, objetivando enfrentar as mudanças na era da globalização. Essas possibilidades indicam um modelo de desenvolvimento territorial baseado nos conceitos de qualidade e especificidade. 0 território torna-se um espaço central de coordenação entre os atores interessados na resolução de problemas produtivos inéditos. As autoridades governamentais têm um papel fundamental neste processo, no entanto, num contexto de globalização assimétrica, a governança parece, ainda, fortemente condicionada pela ideologia economicista, colocando em segundo plano o enfrentamento dos dilemas colocados pela visão ecológica dos limites do crescimento material. Em contrapartida a ética da convivência ecológica levanta a questão do compartilhamento de territórios e de recursos naturais. O Território é um fator vital, fundamental para promover políticas de desenvolvimento (DRAGOMIR et al., 2020; LOPES et al., 2020; MARTíNEZ et al., 2016).

Em essência, o que distingue o desenvolvimento sustentável e o desenvolvimento territorial é a noção de sustentabilidade, que é uma meta ou condição do processo de desenvolvimento sustentável, precisando ser associada à noção de que as gerações futuras têm o direito de desfrutar de um mundo limpo, social e economicamente próspero, bem governado e planejado. O desenvolvimento territorial sustentável 
é extremamente desafiador devido às complexas questões levantadas por todas as suas três dimensões, ou seja, a econômica, a social e a ambiental. As autoridades governamentais têm um papel fundamental neste processo, estabelecendo os objetivos do desenvolvimento territorial sustentável, atuando em colaboração com outras partes relevantes dos diferentes setores da sociedade envolvidos no enfrentamento dos desafios da sustentabilidade (DRAGOMIR et al., 2020; MEDEIROS, 2020; PECQUEUR, 2009).

O planejamento territorial sustentável é fundamental para que nossas sociedades enfrentem o desafio da sustentabilidade, principalmente, de sua interpretação nas escalas regional e local. Território é um fator vital, fundamental para promover políticas de desenvolvimento, pois não incorporar essa matriz biofísica nas fórmulas de desenvolvimento seria um erro de grande magnitude e difícil de compensar. É importante identificar como principal protagonista dos processos de planejamento territorial sustentável, o referido fator território, reconhecendo o seu funcionamento como um sistema, e no qual o espaço livre deve ser um bem a ser preservado (FLORIT, 2019; MARTÍNEZ et al., 2016).

O desenvolvimento local incorpora a perspectiva humanística de valorização da pessoa humana, tornando-a o sujeito efetivo de seu próprio destino. Trata-se, portanto, de um pressuposto lógico, em que as pessoas devem participar ativamente e não serem apenas beneficiárias do desenvolvimento. 0 desenvolvimento humano local e sustentável adota como fundamento a ideia de que toda região territorial possui recursos endógenos, independentemente de sua quantidade ou qualidade, que pode valorizar e administrar de uma perspectiva sistêmica, para melhorar as atuais condições de desenvolvimento humano. Busca estabelecer ações que sejam gerenciadas no território em curto prazo, que devem ser congruentes com uma visão de médio e longo prazo. Também incorpora a visão histórica e cultural como elemento central do processo, bem como a identificação e integração dos atores sociais, governamentais e privados com localização local ou com capacidade de interferência no processo de desenvolvimento (ASATO et al., 2019; HERNÁNDEZ, 2019).

O desenvolvimento local sustentável reforça a valorização dos processos endógenos, haja vista que as regiões não respondem da mesma maneira às políticas de desenvolvimento territorial. É preciso mobilizar o potencial endógeno de cada território, destacando as suas riquezas, as bases institucionais de apoio político, tecnológico e de crédito, assim como as demandas populacionais, a cooperação existente entre agentes locais, as inovações e vocações regionais, e principalmente os atores sociais (MENEZES et al., 2016; SILVA et al., 2019).

Nos conflitos ambientais territoriais, o que está em jogo é a sobreposição da territorialidade de grupos mais poderosos em territórios de grupos subalternizados, como no caso da remoção de populações tradicionais sem que seja oferecida condições de reproduzir suas relações socioambientais. Trata-se, portanto, de um pressuposto lógico, em que as pessoas devem participar ativamente e não serem apenas beneficiárias do desenvolvimento, adotando como fundamento a ideia de que toda região territorial possui recursos endógenos, independentemente de sua quantidade ou qualidade, que pode valorizar e administrar de uma perspectiva sistêmica, para melhorar as atuais condições de desenvolvimento humano e mobilizar o potencial de cada território (ASATO et al., 2019; SPERB et al., 2018). 
É no contexto do território que uma nova geração de políticas públicas tem sido fomentada por atividades socialmente inovadoras que objetivam apresentar soluções aos atuais problemas conjunturais, sendo fundamentais para o desenho de uma nova geração das políticas. Assim, a inovação social é percebida como processo, serviço, produto, motor de mudança no território (ANDION et al., 2017; BITTENCOURT et al., 2016; FONTAN et al., 2004; HILLIER et al., 2004; MOULAERT et al., 2008; RICHARDSON et al., 2014; RONCONI et al., 2019).

A agricultura urbana consiste na realização de atividades agrícolas no interior e nas periferias das cidades, que incluem o cultivo de hortaliças e a pecuária. Em nível global, a agricultura urbana se apresenta como uma alternativa concreta para melhorar a segurança alimentar nas cidades e mitigar o fenômeno dos desertos verdes, embora tenha recebido atenção limitada de planejadores e analistas. Por outro lado, a agricultura urbana pode realizar diversos serviços ecossistêmicos, que além de incluir a produção de alimentos frescos, inclui regulação térmica e mitigação de poluição. Um dos tipos mais comuns são os jardins familiares de quintal. É assim que se dá a produção de espécies hortícolas, realizada em áreas de ligação direta com o local de residência e com forte cunho do trabalho familiar. O principal objetivo destas hortas é o fornecimento de vegetais frescos sazonais às unidades domésticas que as realizam, podendo ser uma estratégia importante para a obtenção de alimentos frescos a nível familiar, uma vez que permitem o acesso a vegetais frescos e proteínas de origem animal, no caso de ser combinada com a criação de animais (LOVELL, 2010; MOUGEOT, 2006; PARÉS, 2009; TORNAGHI, 2014).

As políticas públicas principalmente fomentadas na agricultura urbana têm seu foco sobre a segurança alimentar e nutricional, porém, outras políticas que acabam refletindo em ações na agricultura urbana, assim como políticas ambientais e de planejamento urbano. Destaca-se que a esfera municipal é aquela que deve promover a agricultura urbana, porém, sem a contribuição das demais esferas não é possível viabilizar o estímulo financeiro para desenvolver o setor (AQUINO et al., 2007; MAAS et al., 2020).

As hortas urbanas foram difundidas e podem ser encontradas em todos os continentes. As especificidades das regiões onde são implantadas fazem com que sua adoção tenha diversos objetivos, todavia, a contribuição econômica, ambiental e social é um fator comum em todos os lugares onde elas são encontradas. De maneira geral, foram evidenciados dois agrupamentos principais relacionados à agricultura urbana, que giram em torno dos termos alimento e horta. No agrupamento dos alimentos, destacam-se as relações dos alimentos produzidos no meio urbano com a segurança alimentar, com a questão ambiental e econômica, com a sustentabilidade e com o empoderamento feminino. Também pode ser observada a preocupação com a contaminação dos alimentos no meio urbano e a relação entre os telhados verdes e o sequestro de carbono. Por fim, a análise da cadeia de produção na agricultura urbana é destacada, com seu potencial de reuso de insumos, redução de desperdício e diminuição de custos com o transporte. Já no agrupamento das hortas, observa-se uma relação entre as hortas urbanas e seu planejamento, desenvolvimento, governança, gestão e participação. Existe também uma relação direta com a comunidade, que se relaciona fortemente com direitos civis, engajamento, conhecimento e bem-esta social. Nas cidades, a multifuncionalidade das hortas é evidenciada, assim como sua importância para saúde pública (PULIGHE et 
al., 2016; ROSTAMI et al., 2015).

Observando o papel da agricultura nas grandes cidades, devemos destacar a diferença existente entre as áreas periurbanas, onde a agricultura é principalmente orientada para o mercado com presença de agricultores profissionais e as áreas urbanas, onde a agricultura geralmente se concentra no autoconsumo, com fins recreativos ou sociais (ALIÓ et al., 2015; ALIÓ et al., 2020).

A agricultura urbana é um tema emergente no campo do agronegócio e está cada vez mais presente nas discussões governamentais e acadêmicas. Pela possibilidade de inserção nos mais diversos contextos urbanos, pode conferir à empreendimentos comerciais uma imagem condizente à crescente busca por uma alimentação de maior qualidade. O desenvolvimento de novas formas de inserção e aproveitamento da prática em diferentes modalidades de negócio pode conferir à agricultura urbana um significado cada vez mais abrangente, que vá além da geração de emprego e renda e segurança alimentar, e abarque também nutrição de qualidade, consciência e educação alimentar, respeito e conservação ambiental (LEE-SMITH, 2005; LEONIDOU et al., 2013).

Ao longo de sua estrutura funcional e espacial, as questões do uso do solo e do planejamento urbano também impõe limites. Embora hoje em dia as hortas comunitárias sejam uma característica bastante visível da paisagem urbana, em muitos casos eles nunca foram oficialmente registrados ou incluídos em documentos de ordenamento do território. Assim, da perspectiva das autoridades locais, esses jardins são frequentemente percebidos como se eles existissem. No entanto, ainda, muitos planejadores recusam-se a considerar os jardins comunitários como um uso apropriado de terras públicas, porque a agricultura urbana comunitária, apesar de seus benefícios ambientais e sociais, não é uma atividade economicamente atrativa quando comparada a outros geradores de impostos da terra (CALVET-MIR et al., 2019; KRIKSER et al., 2016; SKAMLOVÁ et al., 2020).

O sucesso da agricultura urbana depende de sua aceitação como uma atividade significativa e permanente. Depende também da incorporação do planejamento do uso da terra e do nível de cooperação entre todos os interessados na comunidade local, incluindo as organizações externas e o governo municipal. Estas iniciativas seguem uma lógica com base em ganhos individuais. Uma combinação de aspirações individuais e coletivas, promovendo a transformação social e urbana. Fazendo uso de espaços atualmente não utilizados, combinando múltiplos objetivos, desenvolvendo novos conceitos e técnicas. Considerada um caminho para resgatar as desigualdades, carece de um reconhecimento especial para permitir a redução das pressões convergentes que comprometem o seu futuro. No nível social e comportamental, aponta para a importância da cocriação de valor entre as empresas, a sociedade civil e o poder público para sustentar e criar valor. A agricultura urbana como parte da infraestrutura urbana verde tem sido cada vez mais proposta como uma solução urbana multifuncional baseada na natureza (MA et al., 2020; OCHOA et al., 2020; SANYÉMENGUAL et al., 2020; PIERINI, 2016).

\section{METODOLOGIA}

No que se refere aos aspectos metodológicos trata-se de pesquisa qualitativa, exploratória, descritiva 
e explicativa, sendo utilizado como meio de investigação o estudo de caso. Os procedimentos metodológicos foram divididos em duas etapas. Na primeira etapa foi adotado o caráter exploratório, com a intenção de ampliar o conhecimento sobre o tema, através de revisão bibliométrica sistemática, realização de entrevistas semiestruturadas e identificação dos dispositivos legais relacionados à agricultura urbana, no âmbito Federal, Estadual e Municipal. Na segunda etapa foi feita uma pesquisa descritiva e explicativa, por meio de análise da revisão bibliométrica sistemática, das entrevistas semiestruturadas e dos dispositivos legais relacionados à agricultura urbana, no âmbito Federal, Estadual e Municipal.

A metodologia aplicada nesta pesquisa foi de caráter qualitativo, já que a realidade analisada é múltipla e subjetiva, sendo que as experiências dos indivíduos e suas percepções são aspectos úteis e importantes para a pesquisa. Sendo assim, o raciocínio ou a lógica da pesquisa qualitativa é a indutiva, partindo de análises específicas para a realização da análise geral (ECO, 2015; PATIAS et al., 2019).

A análise dos dados foi pautada inicialmente pelo caráter descritivo do estudo, buscando atender os objetivos específicos. Para tanto foi necessário analisar a trajetória, o contexto e os processos das iniciativas estudadas. Destacando as variáveis de trajetória, além da reconstituição dos contextos históricos que condicionam a formação de determinadas dinâmicas territoriais de desenvolvimento e inovações sociais (ECO, 2015; SABOURIN, 2011).

$\mathrm{Na}$ análise explicativa o conteúdo foi analisado predominantemente pela técnica de análise de conteúdo, por meio da categorização do conteúdo, buscando compreender as interações, as dinâmicas de inovação, a constituição de redes, bem como os processos de aprendizagens identificados em tais iniciativas. Assim as variáveis de resultados e inclusão de novas abordagens permitem analisar um sistema de inovações sociais em rede, dispostos em sua materialidade socioespacial, possibilitando estimar os impactos, identificar as mudanças geradas no território e a inclusão de novas abordagens, que contribuam com a implantação, avaliação e monitoramento de políticas públicas de inovação social, estimulando o desenvolvimento territorial sustentável (BARDIN, 2010; VERGARA, 2000).

O estudo de caso é um processo metodológico que dá relevo a percepção contextual sem negligenciar a representatividade, focando-se na compreensão dinâmica da realidade local. Tem valor quando as conjunturas são complexas e podem mudar, quando as condições que dizem respeito não foram encontradas antes, quando as situações são demasiadas políticas e onde existem muitos interessados. Na condição de ferramenta de investigação científica, contribui com a percepção contextual sem negligenciar a representatividade e se focou na compreensão dinâmica da realidade local. Na condição de ferramenta de investigação científica, facilitou a compreensão de processos perante a complexidade social nas quais estes se manifestaram. Tanto em situações de limitações quanto na análise de obstáculos, sobretudo, em situações de potencialidades, para a validação de modelos exemplares (CRESWELL, 2007; GIL, 2008; PARKER et al., 2016).

Durante o ano de 2017 foram realizadas 5 entrevistas semiestruturadas com os membros da Diretoria Executiva do Cepagro, sendo gravadas e transcritas. Os entrevistados foram identificados como E1, E2, E3, E4 e E5. A partir dessas interações foi possível mapear os trabalhos desenvolvidos pela organização, 
particularmente os de incidência política. Cumpre destacar que esse estudo se focou na perspectiva que a organização tem sobre sua atuação, isto é, buscou-se identificar a visão dos entrevistados em relação à inovação social no campo da agricultura urbana.

Em 27 de fevereiro de 2021 foi realizada busca na base de dados da Scopus, utilizando os termos de busca 'Social Innovation OR Urban Agriculture' e o resultado foi de 6667 artigos. Utilizando os termos de busca 'Social Innovation AND Urban Agriculture' o resultado da busca foi de 16 artigos, todos citados nesta pesquisa.

No dia 28 de fevereiro de 2021 foi realizada busca na base de dados da Scielo, utilizando os termos de busca 'Social Innovation OR Urban Agriculture' e o resultado foi de 1940 artigos. Utilizando os termos de busca 'Social Innovation AND Urban Agriculture' o resultado da busca foi de 2 artigos, ambos citados nesta pesquisa.

De maneira geral, nas bases de dados da Scopus e da Scielo, utilizando os termos de busca 'Social Innovation OR Urban Agriculture', a revisão bibliométrica encontrou 8607 artigos no total. Utilizando os termos de busca 'Social Innovation AND Urban Agriculture', a revisão bibliométrica encontrou 18 artigos, todos incorporados no referencial teórico desta pesquisa.

Quadro 1: Bibliometria.

\begin{tabular}{|l|l|l|}
\hline Bibliometria & Social Innovation OR Urban Agriculture & Social Innovation AND Urban Agriculture \\
\hline Scopus & 6667 & 16 \\
\hline Scielo & 1940 & 2 \\
\hline Total & 8607 & 18 \\
\hline
\end{tabular}

A análise dos dados foi pautada na matriz teórico-metodológica adotada nesse estudo, que se baseia no esforço de elucidação das relações de interdependência entre as dimensões conceituais e empíricas do estudo. Mobilizou, para efeitos de análise em torno da inovação social no contexto da agricultura urbana as variáveis de contexto, processo e resultado.

Quadro 2: Dimensões da pesquisa.

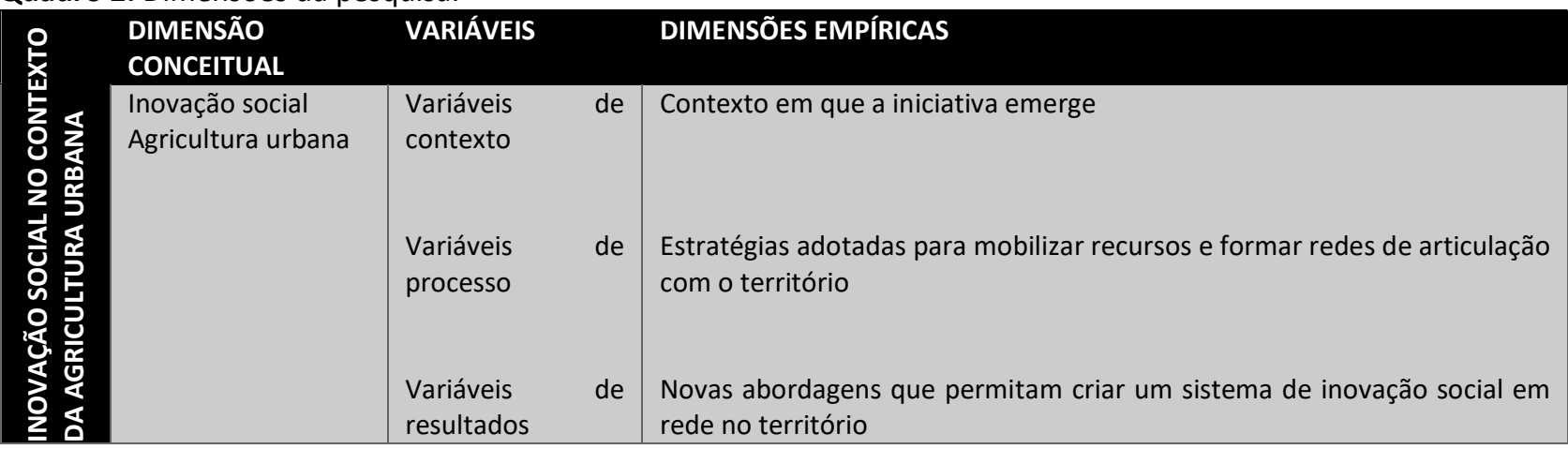

Buscou-se identificar o contexto em que a iniciativa sobre agricultura urbana emergiu no território, os processos desencadeados a partir das diferentes formas de mobilização de recursos e conhecimento, a formação de redes solidárias, parcerias e formas de articulação, ou seja, as novas abordagens que permitem criar um sistema de inovação social em rede no território. 


\section{RESULTADOS E DISCUSSÃO}

\section{O caso do centro de estudos e promoção da agricultura de grupo}

O Cepagro foi criado em 1990 e tem sido reconhecido por sua capacidade de articular, dialogar e incidir politicamente no território de Florianópolis. Sediado dentro do Centro de Ciências Agrária (CCA) da Universidade Federal de Santa Catarina (UFSC) em Florianópolis, é uma ONG referência quando o assunto é fortalecimento da Agroecologia. A organização trabalha através de redes, em comunidades rurais e urbanas, desenvolvendo tecnologias sociais, incentivando e estimulando a formação de redes de apoio a iniciativas da cidade e colaborando para o êxito através de recursos humanos, técnico, materiais e financeiros.

A organização participa de variadas arenas públicas e tem dialogado com as diferentes esferas de sociedade civil e governos, o que favorece a criação e implementação de políticas públicas voltadas para seus grupos de interesse: agricultura familiar e comunidades urbanas. Buscam, assim, desenvolver e dar suporte a diferentes iniciativas de inovação social não só buscando soluções para os problemas de desenvolvimento sustentável mas tendo incidência política e propondo novas políticas públicas em torno dos temas foco de seus trabalhos. A organização possui diversos parceiros e financiadores, inclusive internacionais.

Através do Observatório de Inovação Social de Florianópolis (OBISF), foi possível observar a rede do Cepagro e suas conexões com outros atores do ecossistema de inovação social da cidade. Observou-se tanto iniciativas desenvolvidas pelo Cepagro quanto sua articulação com outras organizações da sociedade civil e com órgãos governamentais, como a Prefeitura Municipal de Florianópolis, a Fundação de Amparo à Pesquisa e Inovação do Estado de Santa Catarina (FAPESC) e o Conselho Municipal de Segurança Alimentar e Nutricional (OBISF, 2019).

Ter incidência política é uma preocupação da organização que participa, com membros da equipe técnica e diretoria do Cepagro, em diferentes conselhos com o objetivo de discutir e cooperar com a construção e acompanhamento das políticas públicas nas áreas da Agroecologia, Produção Orgânica, Alimentação Escolar, Segurança Alimentar e Nutricional, Diversificação da Fumicultura e Gestão de Unidades de Conservação, além do Conselho Estadual de Segurança Alimentar e Nutricional - (CONSEA/SC), do Conselho Municipal de Segurança Alimentar e Nutricional Sustentável - (COMSEAS/Florianópolis), do Conselho Estadual do PRONAF, do Fórum de Políticas Públicas de Florianópolis, da Rede Temática da Diversificação em Áreas Cultivadas com Tabaco e da Rede Semear Floripa de Agricultura Urbana. Nos espaços dos conselhos apresentam propostas, articulam, auxiliam e acompanham o governo na formação de novas políticas públicas para a área de segurança alimentar e nutricional e controle social.

O Cepagro integrou, a partir do Decreto no 16.408 de 2016, o Grupo de Trabalho Intersetorial da Prefeitura de Florianópolis que tinha o objetivo de estudar e propor um Programa Municipal de Agricultura Urbana. Esse Grupo de Trabalho foi composto por representantes de organizações da sociedade civil, por técnicos e especialistas, por Secretarias Municipais, pela Fundação Municipal do Meio Ambiente (FLORAM) e pela Companhia de Melhoramentos da Capital (COMCAP). Através dos debates realizados por esse GT foi elaborado o Decreto 17.688/17, que instituiu o Programa Municipal de Agricultura Urbana de Florianópolis. 
Os membros que compõem a Diretoria Executiva da organização destacaram, durante as entrevistas realizadas nessa pesquisa, que o Cepagro possui apoiadores e financiadores internacionais como a Fundação Interamericana (EUA) e a MISEREOR (Alemanha).

Possuem também parceiros institucionais, como a Universidade Federal de Santa Catarina UFSC com quem, a partir do diálogo com professores, buscam desenvolver ações comuns. Com os entes do Governo (municipal, estadual e federal) as parcerias para o desenvolvimento de projetos se destacam no sentido de apoio financeiro (E1).

O trabalho em rede é intrínseco ao Cepagro e a própria missão da organização enfatiza a importância da rede. É fundamental trabalhar com outras organizações, a exemplo da participação do Cepagro na Rede Ecovida, que é simbólica no tema da Agroecologia (E2).

É necessário estabelecer parcerias, não só em termos, por exemplo, de financiamento, mas também pensando em outros tipos de apoio. A organização trabalha por projeto, dependendo dos editais (E4).

Trabalho em rede é a forma de trabalho utilizada, sempre pensando no seu ecossistema, é o perfil da organização, entendendo que uma ação só é possível se tiver uma rede de relações para avançar (E1).

A participação do Cepagro na Rede SEMEAR é considerada extremamente importante para a questão da agricultura urbana, pois reuniu diversos atores e muitos representantes do Governo simpatizantes com o tema (E1; E2; E3; E4; E5).

Com a perspectiva de ser um espaço de articulação dos agricultores urbanos com organizações da sociedade civil, com o Cepagro e com representantes de órgãos públicos, nasceu em 2015 a Rede SEMEAR (E1).

A Rede Semear é composta por atores do governo, empresas e organizações da sociedade civil, incluindo o Cepagro, foi fundamental para o sucesso desse Grupo de Trabalho. A Rede tem como missão semear a agroecologia para colher uma cidade sustentável e sua visão é viver em uma cidade que fomente a cultura agroecológica, alimentando saúde e qualidade de vida. A participação na rede é aberta para todos os indivíduos que compactuam com seus princípios e que desejam desenvolver e estimular a Agricultura Urbana em Florianópolis.

A importância da rede SEMEAR para a aprovação do Decreto 17.688/2017, que em 05/06/2017 cria o Programa Municipal de Agricultura Urbana. A rede foi fundamental, pois tinha os gestores, representações das hortas comunitárias e representação de quem é o público base. O Programa Municipal foi construído através da Rede SEMEAR. O decreto municipal de Agricultura Urbana foi construído coletivamente a partir de uma comissão intersetorial criada dentro da Prefeitura de Florianópolis. O Cepagro foi convidado a colaborar na elaboração do documento. Em 2017 o Decreto foi assinado pelo Prefeito e o Programa Municipal da Agricultura Urbana foi instituído. A aprovação do Decreto 17.688/2017 é considerada um avanço, já que é um documento que orienta a execução do programa. Todavia, para que o Programa não fique apenas no papel é preciso que seja inserido dentro das Secretarias, com planejamento e orçamento definido. Existe o desafio que esse programa possa ser realmente efetivado a partir de uma política pública, mas precisaria estar mais consolidado. A questão do orçamento é um desafio para efetivar as ações, porque 
uma política pública sem um recurso orçamentário fica no papel. Os diálogos com parceiros são importantes para tentar resolver os impasses enfrentados pelos diferentes projetos. Trabalhar em rede, através de parcerias com outras organizações, comunidades e setor público é fundamental para o Cepagro (E1).

A dinâmica de trabalho pode ser considerada fruto da própria história da organização, que ao longo de 27 anos foi se adequando aos novos tempos, monitorando possíveis inovações, tanto no campo de tecnologias quanto no campo de estrutura organizacional e colaborativa. A agricultura urbana, a agricultura orgânica e a agroecologia foram sendo incorporadas na agenda da organização a partir das articulações em rede e do estabelecimento de parcerias. As parcerias auxiliam e dão suporte para a inovação territorial (E3).

Os entrevistados, de forma unânime, ressaltaram a importância do trabalho em rede pelo Cepagro (E1, E2, E3 e E4). Trabalhar em rede tem vantagens e dificuldades, embora os conflitos estejam presentes nas redes, isso é positivo, porque contribui para mudanças (E2).

A aproximação com a comunidade e com organizações parceiras é salientada pela procura de articulação com a Epagri local, com a escola local, com o sindicato local, porque facilita o contato nas comunidades rurais. Algumas iniciativas exigem a formação de uma rede entre escola, posto de saúde, outros projetos e a comunidade (E4).

Os conflitos nos espaços de encontro do Cepagro com os entes públicos não são conflitos de posições (E1). Os conflitos são referentes ao tempo de execução das ações (E2). O diálogo com os órgãos públicos em alguns momentos é ineficiente, por conta do aparato administrativo burocrático (E4). A incidência política nos espaços de participação é importante nos espaços de conselhos e fóruns para efetivar o controle social (E1).

Muitas das iniciativas da Cepagro independem do poder público, por conta da insuficiência de políticas específicas. Falta continuidade nas políticas públicas. Se um projeto não é renovado, a ação vinculada para (E4)

Os agentes internacionais e a abertura mais recente dos governos, que incorporaram em sua agenda as questões ambientais, abriram caminho para que algumas questões, antes consideradas utópicas, pudessem se transformar em políticas públicas, como no caso da gestão de resíduos e com as alternativas ao cultivo do tabaco (E5).

O Cepagro ocupa vários espaços como os Conselhos de Políticas Públicas, colaborando com intervenções importantes. A organização participou do Conselho da Alimentação Escolar, e ali fez diversas intervenções, em vários temas que foram polêmicos, a exemplo da questão da terceirização. Atuou também na questão da gestão da Política Nacional de Resíduos Sólidos. Nesse tema um membro do Cepagro foi convidado para participar de um GT intersetorial no Ministério do Meio Ambiente com outros órgãos (E1). A participação nos espaços dos Conselhos possibilita compreender a elaboração dos projetos de lei, além de se articular com novos parceiros (E4).

O Cepagro teve um papel fundamental no processo de aprovação em Florianópolis do Programa Municipal de Agricultura, porque é uma das organizações precursoras na agricultura urbana no município (E2). 
Assim, a incidência política tem sido colocada como um objetivo da organização que busca ocupar os espaços institucionalmente constituídos (E3). O Cepagro identifica um problema e busca soluções sua rede de atores envolvidos com uma determinada problemática. Muitas vezes a organização é convidada para discutir a políticas públicas (E2). As políticas públicas são construídas para além das ações governamentais. Assim, a política pública pode ser vista enquanto uma ação pública que consiste numa ação coletiva promovida por diferentes atores públicos e privados, em diferentes âmbitos e níveis decisórios (GONSALVES et al., 2019).

A partir da sua atuação em rede, é possível identificar os problemas públicos e cooperar para que esses problemas sejam resolvidos, a exemplo do projeto da agricultura urbana (E1). Assim, o problema público não é identificado somente a partir do contato do Cepagro com a comunidade, mas a partir da rede na qual a organização está inserida (E3). A inovação social pode ser percebida como processo e como motor de mudança no território, que resulta em novas práticas e formas de pensar e de resolver os problemas públicos (BITTENCOURT et al., 2016).

A participação nos conselhos permite influenciar as políticas públicas, como na aprovação do Decreto da Agricultura Urbana (E3). Pode-se observar que a inovação social em relação à criação de dispositivos legais tem destacado a inteligência coletiva e a produção de conhecimento a partir da experimentação social que age em prol de mudanças pertinentes à dimensão da política pública (FONTAN et al., 2004; HILLIER et al., 2004).

O contexto da cidade é relevante para se pensar a agricultura urbana, em todas as suas vertentes. Desde um telhado verde, uma horta em um quintal, um espaço público de ocupação, um engenho de farinha, uma roça, um cafezal ou hortaliças para a comercialização. Essa aptidão agroecológica que tem é promotora de saúde e qualidade de vida para a cidade (E5).

\section{CONCLUSÕES}

Essa pesquisa buscou identificar a inovação social no contexto da agricultura urbana na cidade de Florianópolis e o papel do Cepagro nesse processo. O Cepagro, a partir de suas redes, tem colocado o tema da agricultura urbana em debate e tem contribuído para que importantes dispositivos legais organizem e promovam essa inovação social no território. $O$ estudo corroborou outras pesquisas que identificam que a política pública pode ser formulada a partir da ação em rede de organizações da sociedade civil não cabendo ao Estado o papel de exclusivo formulador de políticas públicas.

O contexto da cidade de Florianópolis, como espaço para aprendizagem coletiva, criou o ambiente propício para que essa iniciativa emergisse. Deve-se considerar, nesse contexto, tanto a dinâmica associativista do território quanto suas possibilidades cooperativistas, além do engajamento dos próprios atores na busca de soluções para os problemas púbicos da cidade, quanto a preocupação de cidadãos e organizações com as questões relacionadas com qualidade de vida e com a vocação agroecológica da cidade. Florianópolis, enquanto território estudado, apresenta, entre as suas especificidades, a cultura do empreendedorismo. Além disso, Florianópolis tem sido reconhecida como uma cidade frutífera em iniciativas 
de inovação social promovidas tanto por setores da sociedade civil quanto pelo setor público e privado.

As estratégias utilizadas para que dispositivos legais em relação ao tema fossem decretados se referiram a mobilização de diferentes recursos e conhecimentos. O Cepagro participa de inúmeras redes e espaços institucionais e tem articulado essas diferentes redes no território. A organização considera que as redes são fundamentais para a identificação e solução de diferentes problemas públicos, e que a partir das redes é possível ter incidência política, isto é, propor políticas públicas que promovam cidades mais sustentáveis. Assim, foi possível identificar que o tema da agricultura urbana entra na agenda pública a partir do debate entre diferentes atores. Tratou-se de uma aprendizagem coletiva que envolveu múltiplos atores e setores.

Os dados da pesquisa permitiram identificar que em relação ao tema da agricultura urbana novas abordagens têm criado um sistema de inovação social em rede no território. Caracterizando processos de inovação que precisam ser acompanhados por estudos subsequentes. Como alertaram os entrevistados desse estudo, não bastam dispositivos legais, mas é necessário também, planos e projetos para que a agricultura urbana seja consolidada como política pública na cidade de Florianópolis.

O estudo de caso analisado demonstrou que o Cepagro, a partir de um trabalho em rede, tem desenvolvido experiências de inovação social no território. Além de articular a agricultura urbana com o desenvolvimento comunitário e com a segurança alimentar, tem tido incidência política ao colaborar com a elaboração e implementação de políticas públicas para o setor e estar nos espaços de representação, como os conselhos de políticas públicas da cidade.

\section{REFERÊNCIAS}

ALIÓ, M. À.; AZEVEDO, F. F.. La economía social y solidaria en la transición ambiental. Mercator, Fortaleza, v.14, n.3, p.89108, 2015. DOI: http://doi.org/10.4215/RM2015.1403.0006

ALIÓ, M. À.; CASANOVAS, M.; GIACHINO, D.. Environmental Citizen Demands. The manifestos for the agriculture protection in the Metropolitan Regions of Barcelona and the development of the new environmental culture. Sociedade e Territorio, Natal, 29, 1, p.6-39, 2017. DOI: http://doi.org/10.21680/2177-8396.2017v29n1

ANDION, C.; RONCONI, L. F. A.; MORAES, R. L.; GONSALVES, A. K. R.; SERAFIM, L. B. D.. Sociedade civil e inovação social na esfera pública: uma perspectiva pragmatista. Revista de Administração Pública, Rio de Janeiro, v.51, n.3, p.369-387, 2017. DOI: http://doi.org/10.1590/0034-7612143195

AQUINO, A. M.; ASSIS, R. L.. Agricultura orgânica em áreas urbanas e periurbanas com base na agroecologia. Ambiente \& Sociedade, São Paulo, v.10, p.137-150, 2007.

ASATO, T. A.; MARQUES, H. R.; BUZARQUIS, R. M.; BORGES, P. P.. Perspectivas da economia criativa e do desenvolvimento local no Corredor Bioceânico. Interações, Campo Grande, v.20, p.193-210, 2019. DOI: http://doi.org/10.20435/inter.v20iespecial.2559

BARDIN, L.. Análise de conteúdo. Lisboa: Edições 70, 2010.
BITTENCOURT, B. L.; RONCONI, L. F. A.. Políticas de inovação social e desenvolvimento: o caso da Bolsa de Terras. Revista de Administração Pública, Rio de Janeiro, v.50, n.5, p.795818, 2016. DOI: http://doi.org/10.1590/0034-7612151759

CALVET-MIR, L.; MARCH, H.. Crisis and post-crisis urban gardening initiatives from a Southern European perspective: The case of Barcelona. European Urban and Regional Studies, London, v.26, n.1, p.97-112, 2019. DOI: http://doi.org/10.1177/0969776417736098

CRESWELL, J. W.. Qualitative inquiry and research design : Choosing Among Five Approaches. Thousand Oaks: Sage, 2007.

DRAGOMIR, C. C.; FORIS, D.; TITU, A. M.; FORIS, T.. The Role of Intermediaries in Supporting Collaboration for Sustainability: A Model of Commissioning Intervention in the Multi-Stakeholder Collaboration for Sustainable Territorial Development. Sustainability, Bern, v.12, n.6769, p.1-15, 2020. DOI: http://doi.org/10.3390/su12176769

ECO, U.. Como se faz uma tese em ciências humanas. Lisboa: Presença, 2015.

FLORIANÓPOLIS. Decreto n. 16.408, 06 de julho de 2016. Dispõe sobre a instituição de grupo de trabalho para a elaboração de estudo para criação do programa municipal de agricultura urbana. Florianópolis: DOE, 2016. 
FLORIANÓPOLIS. Decreto n. 17.688, 05 de junho de 2017. Dispõe sobre a criação do Programa Municipal de Agricultura Urbana. Florianópolis: DOE, 2017.

FLORIANÓPOLIS. Lei 9.355, 10 de outubro de 2013. Cria a Política Municipal de Segurança Alimentar e Nutricional Sustentável de Florianópolis. Florianópolis: DOE, 2013.

FLORIANÓPOLIS. Lei 10.392, 06 de junho de 2018. Dispõe sobre a Política Municipal de Agroecologia e Produção Orgânica de Florianópolis. Florianópolis: DOE, 2018.

FLORIANÓPOLIS. Lei 9.355, 10 de outubro de 2013. Cria a Política Municipal de Segurança Alimentar e Nutricional Sustentável de Florianópolis. Florianópolis: DOE, 2013.

FLORIT, L. F.. Dos conflitos ambientais à ética socioambiental: um olhar a partir dos povos e comunidades tradicionais. Desenvolvimento e Meio Ambiente, Curitiba, v.52, p.261-283, 2019. DOI:

http://doi.org/10.5380/dma.v52i0.59663

FONTAN, J. M.; KLEIN, J. L.; TREMBLAY, D. G.. Innovation et société: pour élargir l'analyse des effets territoriaux de l'innovation. Géographie, Économie et Société, Paris, v.2, n.6, p.115-128, 2004.

GIL, A. C.. Métodos e Técnicas de Pesquisa Social. São Paulo: Atlas, 2007.

GONSALVES, A. K. R.; ANDION, M. C. M.. Ação pública e inovação social: uma análise do Sistema de Garantia de Direitos da Criança e do Adolescente de FlorianópolisSC. Organizações \& Sociedade, Salvador, v.26, n.89, p.221248, 2019. DOI: http://doi.org/10.1590/1984-9260892

HILLIER, J.; MOULAERT, F.; NUSSBAUMER, J.. Trois essais sur le rôle de l'innovation sociale dans le développement territorial. Géographie, Économie et Société, Paris, v.2, n.6, p.129-152, 2004.

KRIKSER, T.; PIORR, A.; BERGES, R.; OPITZ, I.. Urban Agriculture Oriented towards Self-Supply, Social and Commercial Purpose: A Typology. Land, Bern, v.5, n.28, p.119, 2016. DOI: http://doi.org/10.3390/land5030028

LEE-SMITH, D.. Agropolis: The social, political and environmental dimensions of Urban Agriculture. Ottawa: IDRC, 2005.

LEONIDOU, L. C.; LEONIDOU, C. N.; FOTIADIS, T. A.; ZERITI, A.. Resources and capabilities as drivers of hotel environmental marketing strategy: Implications for competitive advantage and performance. Tourism Management, Amsterdã, v.35, p.94-110, 2013. DOI: http://doi. org/10.1016/i.tourman.2012.06.003

LOPES, G. B. B.; RONCONI, L. F. A.; FARIAS, G. R.; GEWINSKI, K. K. M.. Sustainability in the Management of the Organization "Cooperativa dos Barqueiros Autônomos da Costa da Lagoa". Ambiente: Gestão e Desenvolvimento, Boa Vista, v.13, n.3, p.72-80, 2020. DOI: http://doi.org/10.24979/ambiente.v13i3.705

LOVELL, S. T.. Multifunctional urban agriculture for sustainable land use planning in the United States.
Sustainability, Bern, v.2, p.2499-2522, 2010. DOI: http://doi.org/0.3390/su2082499

MA, Y.; THORNTON, T. F.; MANGALAGIU, D.; LAN, J.; HESTAD, D.; CAPPELLO, E. A.; LEEUW, S. V.. Co-creation, coevolution and co-governance: understanding green businesses and urban transformations. Climatic Change, Bern, v.160, p.621-636, 2020. DOI: http://doi.org/10.1007/s10584-019-02541-3

MAAS, L.; MALVESTITI, R.; GONTIJO, L. A.. O reflexo da ausência de políticas de incentivo à agricultura urbana orgânica: um estudo de caso em duas cidades no Brasil. Cadernos de Saúde Pública, Rio de Janeiro, v.36, n.8, 2020. DOI: http://doi.org/10.1590/0102-311X00134319

MARTÍNEZ, A. F.; TUR, J. N.. Planeamiento territorial sostenible: un reto para el futuro de nuestras sociedades; criterios aplicados. Cadernos Metrópole, São Paulo, v.18, n.37, p.743-763, 2016. DOI: http://dx.doi.org/10.1590/22369996.2016-3706

MEDEIROS, E.. Portugal 2020: An Effective Policy Platform to Promote Sustainable Territorial Development? Sustainability, Bern, v.12, n.1126, p.1-16, 2020. DOI: http://doi.org/10.3390/su12031126

MENEZES, E. C. O.; SERVA, M. R.; RONCONI, L. F. A.. Governança dos recursos de uso comum e desenvolvimento territorial sustentável: análise dos arranjos institucionais da pesca na grande Florianópolis. Revista de Gestão Social e Ambiental, São Paulo, v.10, n.1, 22-40, 2016. DOI: http://doi.org/10.5773/rgsa.v10i1.1109

MOUGEOT, L. J .A.. Cultivando mejores ciudades: agricultura urbana para el desarrollo sostenible. Ottawa: Centro Internacional de Investigaciones para el Desarrollo, 2006.

MOULAERT, F.; MEHMOOD, A.. Analyser le développement régional. Géographie, Économie et Société, Paris, v.2, n.10, p.199-222, 2008.

MULGAN, G.; TUCKER, S.; ALI, R.; SANDERS, B.. Social innovation: what it is, why it matters and how it can be accelerated. London: The Young Foundation, 2007.

OCHOA, C. Y.; RUIZ, A. M.; OLMO, R. M.; FIGUEROA A. M.; Rodríguez, A. T.. Peri-Urban Organic Agriculture and Short Food Supply Chains as Drivers for Strengthening City/Region Food Systems: Two Case Studies in Andalucía. Land, Spain, v.9, n.177, p.1-20, 2020. DOI: http://doi.org/10.3390/land9060177

PARKER, L.; NORTHCOTT, D.. Qualitative generalising in accounting research: concepts and strategies. Accounting, Auditing \& Accountability Journal, London, v.29, n.6, p.1100-1131, 2016. DOI: http://doi.org/10.1108/AAAJ-042015-2026

PARÉS, G.. Las funciones de la agricultura urbana y periurbana en La Matanza, desde la óptica de los propios agricultores, en la primera década del siglo XXI. Tesis (Maestría) - Universidad Nacional de San Martín/Universidad Autónoma de Madrid, La Matanza, 2009.

PATIAS, N. D.; HOHENDORF, J. V.. Critérios de qualidade para artigos de pesquisa qualitativa. Psicologia em Estudo, 
Maringá, n.24, e43536, 2019. DOI:

http://doi.org/10.4025/psicolestud.v24i0.43536

PECQUEUR, B.. A guinada territorial da economia global. Política e Sociedade, v.8, n.14, p.79-105, 2009. DOI: http://doi.org/10.5007/2175-7984.2009v8n14p79

PIERINI, M. M.. La educación rural desde la perspectiva de una historia regional de la Patagonia Austral. Historia de la Educación, Madrid, v.17, n.1, p.23-49, 2016.

RICHARDSON, R.; HEALY, A.; MORGAN, K.. Smart specialisation for regional innovation: WP2 Embracing Social Innovation. SMARTSPEC, Grant agreement ID: 320131. European Commission, 2014.

RONCONI, L. F. A.; MENEZES, E. C. O.; BITTENCOURT, B. L.. Desenvolvimento Territorial Sustentável: Iniciativa de Economia Social e Solidária no Contexto do Turismo. Desenvolvimento em Questão, ljuí, n.49, p.94-111, 2019. DOI: http://dx.doi.org/10.21527/2237-6453.2019.49.94-111

ROSTAMI, R.; LAMIT, H.; KHOSHNAVA, S. M.; ROSTAMI, R.. Successful public places: A case study of historical Persian Gardens. Urban Forestry and Urban Greening, Amsterdã, v.15, p.211-224, 2015.

SABOURIN, E.. Teoria da Reciprocidade e sócio-antropologia do desenvolvimento. Sociologias, Porto Alegre, v.13, n.27, p.24-51, 2011. DOI: http://doi.org/10.1590/S1517$\underline{45222011000200003}$
SANYÉ-MENGUAL, E.; SPECHT, K.; VÁVRA, J.; ARTMANN, M.; ORSINI, F.; GIANQUINTO, G.. Ecosystem Services of Urban Agriculture: Perceptions of Project Leaders, Stakeholders and the General Public. Sustainability, Bern, v.12, p.1-23, 2020. DOI: http://doi.org/10.3390/su122410446

SILVA, L. E.; MOURA, E. A.; MENEZES, E. C. O.; OLIVEIRA, A. L.. Desenvolvimento Territorial Sustentável pela Perspectiva da Pesca Artesanal: a realidade da Ponta Oeste da Ilha do Mel, Paraná, Brasil. Interações, Campo Grande, v.20, n.4, p.1195-1215, 2019. DOI:

http://doi.org/10.20435/inter.v20i4.1870

SKAMLOVÁ, L.; WILKANIEC, A.; SZCZEPAŃSKA, M.; BACIK, E.; HENCELOVÁ, P.. The development process and effects from the management of community gardens in two post-socialist cites: Bratislava and Poznań. Urban Forestry \& Urban Greening, Amsterdã, v.48, p.1-13, 2020. DOI: http://doi.org/10.1016/j.ufug.2019.126572

SPERB, M. P.; SERVA, M.. Economia Social e Solidária, Governança e Turismo no Âmbito do Desenvolvimento Territorial Sustentável. Revista de Ciências da Administração, Florianópolis, v.20, n.50, p.93-109, 2018. DOI: http://dx.doi.org/10.5007/2175-8077.2018 V20n50p93

TORNAGHI, C.. Critical geography of urban agriculture. Progress in Human Geography, Washington, v.38, p.551567, 2014.

VERGARA, S. C.. Projetos e relatórios de pesquisa em administração. São Paulo: Atlas, 2000.

A CBPC - Companhia Brasileira de Produção Científica (CNPJ: 11.221.422/0001-03) detém os direitos materiais desta publicação. Os direitos referem-se à publicação do trabalho em qualquer parte do mundo, incluindo os direitos às renovações, expansões e disseminações da contribuição, bem como outros direitos subsidiários. Todos os trabalhos publicados eletronicamente poderão posteriormente ser publicados em coletâneas impressas sob coordenação da Sustenere Publishing, da Companhia Brasileira de Produção Científica e seus parceiros autorizados. Os (as) autores (as) preservam os direitos autorais, mas não têm permissão para a publicação da contribuição em outro meio, impresso ou digital, em português ou em tradução. 